Article

\title{
Radiotherapy in the Management of Non-Metastatic Inflammatory Breast Cancers: A Retrospective Observational Study
}

\author{
Benjamin Nicaise ${ }^{1,2, *}$, Pierre Loap ${ }^{1,3}$, Delphine Loirat ${ }^{3}$, Fatima Laki ${ }^{4}$, Jean-Yves Pierga ${ }^{3}$, Alain Fourquet ${ }^{1}$ \\ and Youlia Kirova $1,5, *$ (D) \\ 1 Department of Radiation Oncology, Institut Curie, 75005 Paris, France; pierre.loap@curie.fr (P.L.); \\ alain.fourquet@curie.fr (A.F.) \\ 2 Faculty of Medicine, Sorbonne Université, 75006 Paris, France \\ 3 Department of Medical Oncology, Institut Curie, 75005 Paris, France; delphine.loirat@curie.fr (D.L.); \\ jean-yves.pierga@curie.fr (J.-Y.P.) \\ 4 Department of Surgery, Institut Curie, 75005 Paris, France; fatima.laki@curie.fr \\ 5 Faculty of Medicine, Université de Versailles Saint-Quentin-en-Yvelines, 78000 Versailles, France \\ * Correspondence: nicaise.benjamin@curie.fr (B.N.); youlia.kirova@curie.fr (Y.K.)
}

Citation: Nicaise, B.; Loap, P.; Loirat, D.; Laki, F.; Pierga, J.-Y.; Fourquet, A.; Kirova, Y. Radiotherapy in the Management of Non-Metastatic Inflammatory Breast Cancers: A Retrospective Observational Study. Cancers 2022, 14, 107. https:// doi.org/10.3390/cancers14010107

Academic Editor: Michael Pinkawa

Received: 27 November 2021

Accepted: 23 December 2021

Published: 27 December 2021

Publisher's Note: MDPI stays neutral with regard to jurisdictional claims in published maps and institutional affiliations.

Copyright: (C) 2021 by the authors. Licensee MDPI, Basel, Switzerland. This article is an open access article distributed under the terms and conditions of the Creative Commons Attribution (CC BY) license (https:// creativecommons.org/licenses/by/ $4.0 /)$.
Simple Summary: Inflammatory breast cancer (IBC) is a rare and aggressive clinicopathological presentation of breast cancer. The treatment of non-metastatic IBC usually consists of neoadjuvant systemic therapy, total mastectomy with axillary lymph node dissection, and adjuvant radiotherapy. This single-center retrospective study aims to assess the clinical outcomes of curative-intent multidisciplinary treatment of non-metastatic IBC. We identified 113 patients with a 5-year overall survival of $78.0 \%$ and a 5-year locoregional recurrence-free survival of $85.2 \%$, highlighting a high locoregional control with standard fractionation $3 \mathrm{D}$ electron or photon therapy in our cohort, despite a pejorative overall survival.

Abstract: (1) Background: Inflammatory breast cancers (IBC) are characterized by a poor prognosis. This retrospective study aims to describe the clinical outcomes of non-metastatic IBC patients treated with a multidisciplinary approach with neo-adjuvant chemotherapy, surgery, and radiotherapy. (2) Methods: This single-center retrospective study included all women patients diagnosed with non-metastatic IBC between January 2010 and January 2018 at the Institut Curie (Paris, France) and treated with neoadjuvant chemotherapy, surgery, and radiotherapy. Overall survival (OS), disease-free survival (DFS), and locoregional free survival (LRRFS) were calculated from the time of diagnosis. Prognostic factors for patient survival were analyzed based on univariate and multivariate regressions. (3) Results: We identified 113 patients with a median age of 51 years. $79.7 \%$ had node-positive tumors; triple-negative breast cancers (TNBC) represented $34.6 \%$ of the cases. A large majority of patients $(91.2 \%)$ received adjuvant post-mastectomy while ten patients $(8.8 \%)$ received preoperative radiotherapy. Non-pathological complete response (non-pCR) was observed in $67.3 \%$ of patients. Radiotherapy delivered a median dose of $50 \mathrm{~Gy}$ to the breast or the chest wall in 25 fractions. With a median follow-up of 54 months, 5-year OS, DFS and LRRFS were 78\% (CI: 70.1-86.8\%), 68.1\% (59.6-77.7\%), and 85.2\% (78.4-92.7\%), respectively. In multivariate analysis, non-pCR was an adverse prognosis factor for OS, DFS, and LRRFS; pre-operative radiotherapy was an adverse prognosis factor for OS and DFS. Radiation-related adverse events were limited to acute skin toxicity ( $22 \%$ of Grade 2 and $2 \%$ of grade 3 dermatitis); no late radiation-induced toxicity was reported. (4) Conclusions: High locoregional control could be achieved with multidisciplinary management of non-metastatic IBC, suggesting the anti-tumor efficacy of radiotherapy in this rare but pejorative clinicopathological presentation. While comparing favorably with historical cohorts, OS and DFS could be potentially improved in the future with the use of new systemic treatments, such as PARP-inhibitors or immunotherapy. 
Keywords: inflammatory breast cancers; triple-negative breast cancers; post-mastectomy radiation therapy

\section{Introduction}

Inflammatory breast cancer (IBC) is a rare clinicopathological presentation of breast cancers (BC), representing only $2.0 \%$ of all incident $\mathrm{BC}$ cases [1], characteristic pathological features of which include diffuse tumor emboli in dermal lymphatic vessels. This entity is classified as T4d in the AJCC 8th edition TNM [2]: clinical features must include erythema, edema, or peau d'orange encompassing more than one-third of the breast and must have developed in the last six months, thus excluding secondary inflammation related to locally advanced breast cancers.

IBC are characterized by a poor prognosis compared to non-inflammatory BC, with 5-year overall survivals ranging from 50 to $65 \%$ in historical cohorts [3-9], because of a high risk of rapid progression and distant dissemination. Yet almost $70 \%$ of patients are diagnosed at a locoregional stage [10] and thus are candidates for a curative intent treatment. Treatment of non-metastatic IBC usually includes neo-adjuvant chemotherapy, followed by total mastectomy with axillary lymph node dissection and adjuvant radiotherapy. This multidisciplinary management often called trimodality is the standard of care, which is supported by retrospective studies showing a survival benefit with this strategy $[5,11]$.

Neo-adjuvant systemic treatment regimens are the same as recommended in non-IBC.

Radiotherapy of the chest wall and lymph node areas is usually performed via standard fractionation [4,6]. A technique using electron field plus bolus for chest wall irradiation and a mix of photons and electrons without bolus for the internal mammary chain (IMC) has been used at our institution since 2007 [12]. This technique showed a benefit on locoregional control at 5 years compared to chest wall irradiation with photons [13], but T4 accounted for only $1 \%$ of our retrospective cohort.

Here we present a retrospective observational study aiming to describe the clinical outcomes of non-metastatic IBC patients treated with a multidisciplinary approach at our institution in the past decade.

\section{Materials and Method}

We identified women patients over the age of 18 who were diagnosed between January 2010 and January 2018 and were treated at our institution with multidisciplinary management for T4d non-metastatic breast cancer according to the AJCC 8th edition TNM. We excluded patients with metastatic disease at diagnosis or before the beginning of locoregional treatment, and patients who did not undergo either neo-adjuvant systemic therapy or radiotherapy.

Institutional review board approval was obtained (CRI-DATA\#200146).

Receptor status was based on the biopsy made at our center. If a patient was first diagnosed outside without a second biopsy or proofreading at our center, we relied on the results found by private practice pathologists. Hormone receptor expression was considered positive if estrogen receptor (ER) or progesterone receptor (PR) expression was $1 \%$ or more. Tumors were considered HER2 positive if the immunohistochemical staining score was $3+$ or if FISH was positive.

Nodal status was defined according to clinical data and the combination of the different imaging modalities available (mammogram, echogram, MRI, and/or PET-CT). If a mass was visible on breast imaging, its largest diameter was recorded (in millimeter) as well as the response to neoadjuvant systemic treatment according to RECIST.

Precise treatment modalities were reported: type of chemotherapy regimen in neoadjuvant, concomitant to radiotherapy or adjuvant setting; use of HER2 inhibitors and hormone therapy; type of surgery; radiotherapy with prescribed dose, fractionation, target volumes, use of electron or photon fields and technique. 
The dosimetric technique used at one of our sites was 3D-conformal electron radiotherapy to the chest wall with bolus adapted to chest wall thickness. Bolus was cut in its medial part to allow electrons to reach IMC. A photon field was added to target IMC while the other lymph node areas were treated exclusively with photons. Patients treated at another of our sites received chest wall irradiation with tangential photon field without bolus and a contribution of photons and electrons to IMC. Rotational IMRT techniques were used in case of particular anatomy or large volumes potentially leading to dosimetric problems. Irradiation of Berg level I was performed in case of positivity of more than $50 \%$ of lymph nodes in axillary dissection.

Some patients underwent standard photon radiotherapy outside of our institution.

Pathological response on the surgical piece was defined preferentially by RCB score, with an RCB score of 0 corresponding to pathological complete response (pCR). Whenever RCB score was not available or computable, pathological complete response was defined according to Sataloff classification and must therefore correspond to TA (total or near therapeutic effect on primary tumor) and NA (evidence of therapeutic effect without residual tumor on axillary nodes).

Survival endpoints were calculated from the time of diagnosis. We used definitions of the STEEP statement [14]. Overall survival events were: death from breast cancer and death from non-breast cancer cause. Disease-free survival (DFS) events were: invasive (or in situ) ipsilateral breast tumor recurrence, locoregional invasive recurrence, distant recurrence, death from breast cancer, death from non-breast cancer cause, or second primary invasive non-breast cancer. Locoregional recurrence-free survival (LRRFS) events were: invasive (or in situ) ipsilateral breast tumor recurrence and locoregional invasive recurrence.

Acute and late radiotherapy-related toxicity were retrospectively recorded according to Common terminology criteria for adverse events version 5 (CTCAE v5).

For the description of population, treatments, and toxicity, quantitative parameters were described with median value and range (minimum-maximum) while qualitative parameters were mentioned with proportions. Survival analyses were performed using Kaplan-Meyer method. Relationship between LRRFS, DFS, OS, and clinical characteristics were evaluated using the Cox regression model: we performed multivariate analysis adjusted for age, clinical nodal status, tumoral diameter on imaging (mm), histologic subtype, histologic grade, RECIST response, pathological response, a capsular rupture in lymph nodes, radiotherapy setting, type of radiotherapy beam (electron of photon) and interruption of radiotherapy. The statistical significance threshold was set at 0.05 . Statistical analyses were performed using R 4.0.3 software, based on the "epiR" and "survminer" packages.

\section{Results}

\subsection{Population}

From January 2010 to January 2018, 113 patients were treated for a non-metastatic IBC in a curative intent with neo-adjuvant systemic treatment, radiotherapy with or without surgery (Table 1).

The median age was 51 years (range 26-89 years). Median Body mass index (BMI) was located in overweight (26.7 (18.4-45.0)). Five patients were carriers of germline BRCA1 mutations $(4.4 \%)$, while one patient had a germline BRCA2 mutation identified $(0.1 \%)$.

Ninety patients $(79.7 \%$ ) had a regional nodal involvement at diagnosis. The large majority was ductal invasive carcinoma (93.8\%). Ki67 proliferation index was high (median $40 \%)$ and there was a majority of grade III tumors $(60.2 \%)$.

The histologic subtype repartition was as follows: $44.2 \%$ hormone receptor-positive/HER negative (HR+/HER2-), 34.6\% triple-negative (TNBC), and 21.2\% HER2 positive (HER2+). 
Table 1. Demographic characteristics.

\begin{tabular}{|c|c|c|c|}
\hline Age (median (range)) & $\begin{array}{c}\text { Median (Range) } \\
51(26-89)\end{array}$ & \multicolumn{2}{|c|}{$\begin{array}{l}\text { Number of Patients }(n=113) \\
\text { Proportion }\end{array}$} \\
\hline BMI (median (range)) & $26.7(18.4-45.0)$ & & \\
\hline \multicolumn{4}{|l|}{ Genetic predisposition } \\
\hline BRCA1 mutation & & 5 & $4.4 \%$ \\
\hline BRCA2 mutation & & 1 & $0.1 \%$ \\
\hline Unknown & & 107 & $96.5 \%$ \\
\hline \multicolumn{4}{|l|}{ Clinical stage } \\
\hline $\mathrm{T} 4 \mathrm{~d} \mathrm{~N}-$ & & 23 & $20.3 \%$ \\
\hline $\mathrm{T} 4 \mathrm{~d} \mathrm{~N}+$ & & 90 & $79.7 \%$ \\
\hline \multicolumn{4}{|l|}{ Histological type } \\
\hline Ductal & & 106 & $93.8 \%$ \\
\hline Lobular & & 7 & $6.2 \%$ \\
\hline Ki67 (median (range)) & $40(0-95)$ & & \\
\hline \multicolumn{4}{|l|}{ Histological grade (SBR) } \\
\hline I & & 3 & $2.7 \%$ \\
\hline II & & 40 & $35.4 \%$ \\
\hline III & & 68 & $60.2 \%$ \\
\hline $\mathrm{NA}^{1}$ & & 2 & $1.7 \%$ \\
\hline \multicolumn{4}{|l|}{ Receptor status } \\
\hline HR+/HER2- & & 50 & $44.2 \%$ \\
\hline HER2+ & & 24 & $21.2 \%$ \\
\hline $\mathrm{HR}+/ \mathrm{HER} 2+$ & & 12 & $10.6 \%$ \\
\hline HR - /HER2+ & & 12 & $10.6 \%$ \\
\hline Triple-negative & & 39 & $34.6 \%$ \\
\hline \multicolumn{4}{|l|}{ Pathological response } \\
\hline $\begin{array}{l}\text { Pathological complete response } \\
\text { (pCR) }\end{array}$ & & 37 & $32.7 \%$ \\
\hline Non-pCR & & 76 & $67.3 \%$ \\
\hline
\end{tabular}

${ }^{1}$ data not available.

\subsection{Treatments}

All but 3 patients underwent a total mastectomy and all but 4 underwent axillary dissection (Table 2).

According to eligibility criteria, neo-adjuvant systemic treatment was administered in all patients, with a high proportion of taxanes and anthracycline-containing regimens. Chemotherapy was administered concurrently with radiotherapy in 17 patients (15.0\%) predominantly with $5 \mathrm{FU}$-vinorelbine (12 patients) or capecitabine alone (5 patients). Adjuvant chemotherapy was given in 6 patients including 3 who received adjuvant capecitabine. Fifty-three percent received adjuvant hormone therapy.

Twenty-four patients received HER2 inhibitors. Six patients received an association of trastuzumab and pertuzumab in the neoadjuvant setting. All of these patients had maintenance with trastuzumab alone except one who received TDM-1.

According to eligibility criteria, radiotherapy was given to all patients but only ten patients $(8.8 \%)$ underwent preoperative radiotherapy. Radiotherapy delivered a median dose of 50 Gy (36-52) with a median dose per fraction of 2 Gy (18-29). Berg lymph node levels II, III, and IV and internal mammary chain were targeted in the majority of patients, and level I was targeted in only $21.2 \%$. Very few boosts to the scar or nodules were given $(5.3 \%)$. The main technique was 3D-conformal radiotherapy $(90.3 \%)$. Thirty-four patients received an electron field to the chest wall (with photons and electrons to the IMC and photons to the other node areas) according to the dosimetric technique described earlier. The other 65 patients with dosimetric data available received photon fields without 
electrons to the chest wall (with photons and electrons to the IMC in 30 patients, electrons alone to the IMC in 4 patients, photons alone to the IMC in 24 patients, and photons to the other node areas). Eleven patients were treated with rotational intensity-modulated radiation therapy (VMAT or helical tomotherapy).

Table 2. Treatment details.

\begin{tabular}{|c|c|c|c|}
\hline Systemic treatment & Median (Range) & \multicolumn{2}{|c|}{$\begin{array}{l}\text { Number of Patients }(n=113), \\
\text { Proportion }\end{array}$} \\
\hline Neoadjuvant & & 113 & $100 \%$ \\
\hline Anthracycline-containing & & 104 & $92.0 \%$ \\
\hline Taxane-containing & & 111 & $98.2 \%$ \\
\hline Cyclophosphamide-containing & & 108 & $95.6 \%$ \\
\hline 5FU-containing & & 68 & $60.2 \%$ \\
\hline Carboplatin-containing & & 1 & $0.9 \%$ \\
\hline Bevacizumab-containing & & 2 & $1.8 \%$ \\
\hline Concomitant with radiotherapy & & 17 & $15.0 \%$ \\
\hline 5FU-Vinorelbine & & 12 & \\
\hline Capecitabine & & 5 & \\
\hline Bevacizumab & & 1 & \\
\hline Adjuvant & & 6 & $5.3 \%$ \\
\hline Capecitabine & & 3 & $2,7 \%$ \\
\hline Other ${ }^{1}$ & & 3 & $2.7 \%$ \\
\hline HER2 inhibitors & & 24 & $21.2 \%$ \\
\hline Trastuzumab-Pertuzumab & & 6 & $5.3 \%$ \\
\hline TDM1 & & 1 & $0.9 \%$ \\
\hline Hormone therapy & & 62 & $5.3 \%$ \\
\hline \multicolumn{4}{|l|}{ Surgery } \\
\hline Mastectomy & & 110 & $97.3 \%$ \\
\hline Breast-conserving surgery & & 2 & $2.7 \%$ \\
\hline Axillary dissection & & 109 & $96.5 \%$ \\
\hline Sentinel lymph node biopsy & & 3 & $3.5 \%$ \\
\hline No surgery & & 1 & $0.1 \%$ \\
\hline \multicolumn{4}{|l|}{ Radiotherapy } \\
\hline \multicolumn{4}{|l|}{ Setting } \\
\hline Preoperative & & 10 & $8.8 \%$ \\
\hline Adjuvant & & 103 & $91.2 \%$ \\
\hline \multicolumn{4}{|l|}{ Regimen } \\
\hline Dose (Gy (range)) & $50(36-52)$ & & \\
\hline Fractions (range) & $25(18-29)$ & & \\
\hline \multicolumn{4}{|l|}{ Target volumes } \\
\hline Chest wall/breast & & 113 & $100 \%$ \\
\hline Boost (scar/nodules) & & $6(4 / 2)$ & $5.3 \%$ \\
\hline Berg's I lymph node & & 24 & $21.2 \%$ \\
\hline Berg's II-III lymph node & & 100 & $88.5 \%$ \\
\hline Berg's IV lymph node & & 101 & $89.4 \%$ \\
\hline Internal mammary chain & & 96 & $85.0 \%$ \\
\hline \multicolumn{4}{|l|}{ Technique } \\
\hline $3 \mathrm{D}$ & & 102 & $90.3 \%$ \\
\hline Electrons (chest wall) & & 34 & $30.1 \%$ \\
\hline Photons (chest wall) & & 52 & $46 \%$ \\
\hline With photons and electrons to IMC & & 30 & $26.5 \%$ \\
\hline With electrons to IMC & & 4 & $3.5 \%$ \\
\hline With photons to IMC & & 13 & $11.5 \%$ \\
\hline $\mathrm{NA}^{2}$ & & 14 & $12.4 \%$ \\
\hline VMAT & & 3 & $2.7 \%$ \\
\hline Tomotherapy & & 8 & $7.0 \%$ \\
\hline
\end{tabular}

${ }^{1}$ Olaparib (1), everolimus (1), oral cyclophosphamide (1); ${ }^{2}$ complete dosimetric data not available. 


\subsection{Outcomes}

With a median follow-up of 54 months, 5-year OS, DFS, and LRRFS were 78\% (CI: $70.1-$ $86.8 \%$ ), 68.1\% (59.6-77.7\%), and 85.2\% (78.4-92.7\%), respectively (Figure 1). A pathological complete response rate of $32.7 \%$ was observed.

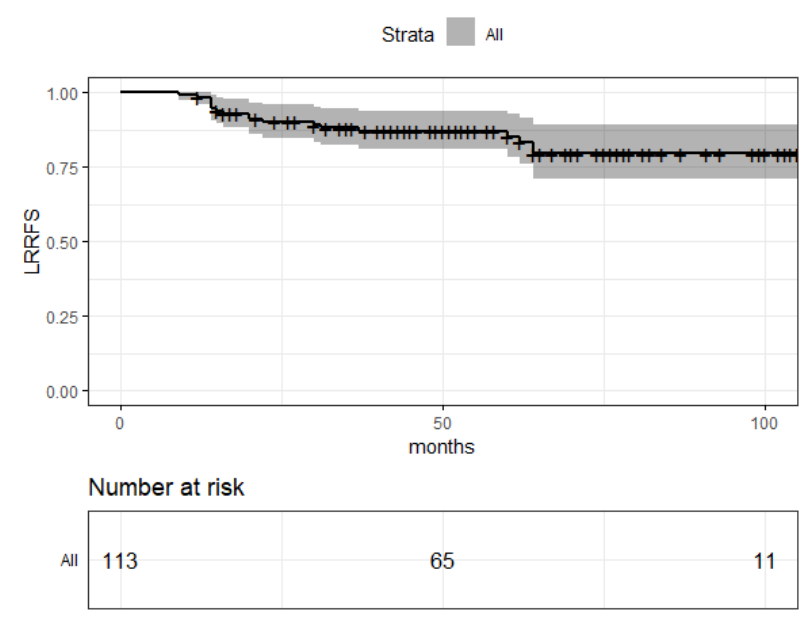

(a)

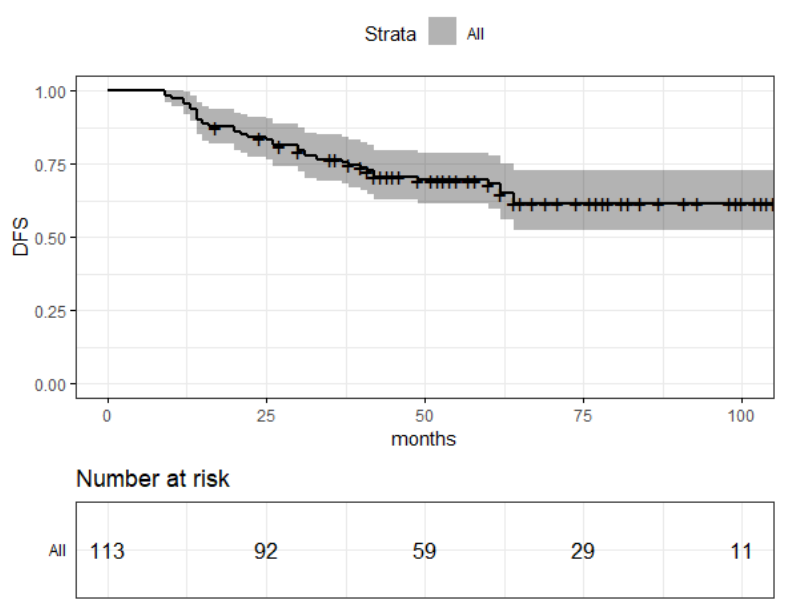

(b)

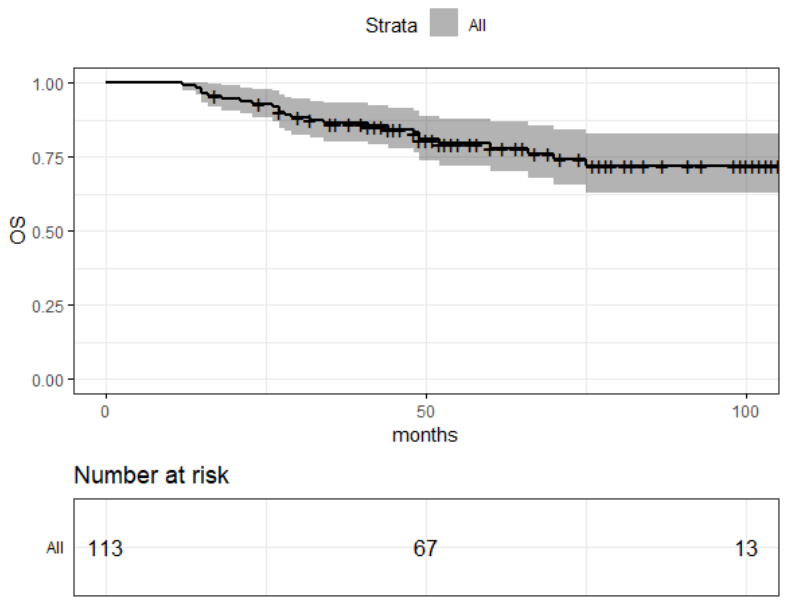

(c)

Figure 1. Survival outcomes: (a) LRRFS; (b) DFS; (c) OS. 
Results from the univariate analysis are reported in Table 3; variables that were significant in univariate analysis were included in multivariate analysis.

Non-pCR was an adverse prognosis factor for OS, DFS and LRRFS $(p<0.01, p<0.01$ and $p<0.01$, respectively) both in univariate and multivariate analyses (multivariate adjusted HR $=4.40$ for OS (95\%CI: 1.42-21.85; $p=0.007)$; HR = 6.06 for DFS (95\%CI: 2.31-22.39; $p=0.001) ; \mathrm{HR}=17.34$ for LRRFS (95\%CI: 2.29-2222.44; $p=0.002)$ ). Pre-operative radiotherapy was an adverse prognosis factor for OS and DFS ( $p<0.01$ and $p<0.01$, respectively), both in univariate and multivariate analyses (multivariate adjusted $\mathrm{HR}=5.22$ for OS (95\%CI: 1.94-12.38; $p=0.02)$; HR = 3.81 for DFS (95\%CI: 1.58-8.07; $p=0.002)$. Suspension of radiotherapy was an adverse prognosis factor for OS in univariate analysis but did not remain significant in multivariate analysis (multivariate adjusted $\mathrm{HR}=2.66$ (95\%CI: 0.93-6.43; $p=0.07)$ ); capsular rupture in lymph node metastases was an adverse prognosis factor for LRRFS in univariate analysis but did not remain significant in multivariate analysis (multivariate adjusted HR = 2.12 (95\%CI: 0.77-5.32; $p=0.14)$ ). Neither diameter of the mass on breast imaging or use of electron beams for chest wall radiotherapy were found to be predictive of survival (Table 3).

Survival curves in adjuvant vs. preoperative radiotherapy setting (Figures A1-A3) and in pCR vs. non-pCR subgroup (Figures A4-A6) are shown in Appendix A.

Table 3. Univariate analyses of prognostic factors for locoregional recurrences, disease-free survival, and overall survival.

\begin{tabular}{|c|c|c|c|c|c|c|}
\hline & \multicolumn{2}{|l|}{ 5-Year LRRFS } & \multicolumn{2}{|l|}{ 5-Year DFS } & \multicolumn{2}{|l|}{ 5-Year OS } \\
\hline & HR & $p$-Value & HR & $p$-Value & HR & $p$ Value \\
\hline Age & $1.09(0.43-2.74)$ & 0.859 & $1.14(0.6-2.15)$ & 0.687 & $0.85(0.39-1.88)$ & 0.69 \\
\hline$<50$ years & $\begin{array}{c}85.77 \% \\
(75.91-96.91 \%)\end{array}$ & & $\begin{array}{c}69.36 \% \\
(57.87-83.13 \%)\end{array}$ & & $\begin{array}{c}73.74 \% \\
(62.44-87.09 \%)\end{array}$ & \\
\hline$>50$ years & $\begin{array}{c}84.25 \% \\
(74.77-94.93 \%) \\
\end{array}$ & & $\begin{array}{c}65.95 \% \\
(53.89-80.72 \%) \\
\end{array}$ & & $\begin{array}{c}82.74 \% \\
(72.31-94.66 \%) \\
\end{array}$ & \\
\hline $\mathrm{cN}$ & $2.17(0.5-9.45)$ & 0.301 & $0.79(0.37-1.66)$ & 0.526 & $0.45(0.2-1.01)$ & 0.052 \\
\hline $\mathrm{N}-$ & $\begin{array}{c}91.3 \% \\
(80.49-100 \%)\end{array}$ & & $\begin{array}{c}57.54 \% \\
(39.55-83.72 \%)\end{array}$ & & $\begin{array}{c}60.47 \% \\
(42.14-86.78 \%)\end{array}$ & \\
\hline $\mathrm{N}+$ & $\begin{array}{c}83.71 \% \\
(75.7-92.57 \%)\end{array}$ & & $\begin{array}{c}70.63 \% \\
(61.41-81.24 \%)\end{array}$ & & $\begin{array}{c}82.87 \% \\
(74.97-91.59 \%)\end{array}$ & \\
\hline $\begin{array}{l}\text { Tumoral diameter } \\
\text { on imaging }(\mathrm{mm})\end{array}$ & $1(0.98-1.02)$ & 0.910 & $0.99(0.98-1.01)$ & 0.367 & $1(0.98-1.02)$ & 0.763 \\
\hline Grade & $1.15(0.43-3.08)$ & 0.778 & $0.75(0.39-1.43)$ & 0.380 & $0.82(0.36-1.84)$ & 0.623 \\
\hline I-II & $\begin{array}{c}83.88 \% \\
(70.32-100 \%)\end{array}$ & & $\begin{array}{c}59.4 \% \\
(44.5-79.29 \%)\end{array}$ & & $\begin{array}{c}78.65 \% \\
(66.22-93.4 \%)\end{array}$ & \\
\hline III & $\begin{array}{c}84.5 \% \\
(76.07-93.86 \%)\end{array}$ & & $\begin{array}{c}71.45 \% \\
(61.35-83.22 \%)\end{array}$ & & $\begin{array}{c}77.14 \% \\
(67.11-88.67 \%)\end{array}$ & \\
\hline Histology & $1.72(0.68-4.35)$ & 0.255 & $1.46(0.76-2.81)$ & 0.253 & $2.12(0.97-4.66)$ & 0.061 \\
\hline $\mathrm{HR}+$ or HER2+ & $\begin{array}{c}88.99 \% \\
(81.3-97.41 \%)\end{array}$ & & $\begin{array}{c}71.53 \% \\
(61.27-83.5 \%)\end{array}$ & & $\begin{array}{c}83.64 \% \\
(74.65-93.72 \%)\end{array}$ & \\
\hline TNBC & $\begin{array}{c}77.93 \% \\
(65.46-92.77 \%)\end{array}$ & & $\begin{array}{c}61.54 \% \\
(48.02-78.87 \%)\end{array}$ & & $\begin{array}{c}67.76 \% \\
(54.06-84.92 \%)\end{array}$ & \\
\hline RECIST & $2.04(0.52-7.97)$ & 0.304 & $1.79(0.74-4.31)$ & 0.193 & $2.26(0.77-6.64)$ & 0.138 \\
\hline $\mathrm{CR} / \mathrm{PR}$ & $\begin{array}{c}88.82 \% \\
(80.44-98.06 \%)\end{array}$ & & $\begin{array}{c}71.86 \% \\
(61.14-84.45 \%)\end{array}$ & & $\begin{array}{c}85.19 \% \\
(76.65-94.68 \%)\end{array}$ & \\
\hline $\mathrm{SD} / \mathrm{PD}$ & $\begin{array}{c}88.24 \% \\
(74.18-100 \%)\end{array}$ & & $\begin{array}{c}63.09 \% \\
(43.32-91.88 \%) \\
\end{array}$ & & $\begin{array}{c}72.4 \% \\
(52.11-100 \%)\end{array}$ & \\
\hline Tumor response & $3.03(1.47-20.63)$ & $<0.01$ & $7.28(2.24-23.66)$ & 0.001 & $6.14(1.45-26.03)$ & 0.014 \\
\hline $\mathrm{pCR}$ & $\begin{array}{c}100 \% \\
(100-100 \%)\end{array}$ & & $\begin{array}{c}91.18 \% \\
(82.09-100 \%)\end{array}$ & & $\begin{array}{c}94.36 \% \\
(87.07-100 \%)\end{array}$ & \\
\hline Non-pCR & $\begin{array}{c}77.86 \% \\
(68.26-88.8 \%)\end{array}$ & & $\begin{array}{c}57.11 \% \\
(46.6-70 \%)\end{array}$ & & $\begin{array}{c}70.32 \% \\
(59.94-82.49 \%)\end{array}$ & \\
\hline
\end{tabular}


Table 3. Cont.

\begin{tabular}{|c|c|c|c|c|c|c|}
\hline & \multicolumn{2}{|l|}{ 5-Year LRRFS } & \multicolumn{2}{|l|}{ 5-Year DFS } & \multicolumn{2}{|l|}{ 5-Year OS } \\
\hline & HR & $p$-Value & HR & $p$-Value & HR & $p$ Value \\
\hline Capsular rupture & $3.46(1.3-9.22)$ & 0.013 & $1.95(0.89-4.25)$ & 0.095 & $1.29(0.44-3.75)$ & 0.645 \\
\hline No & $\begin{array}{c}89.59 \% \\
(83.67-95.92 \%)\end{array}$ & & $\begin{array}{c}71.56 \% \\
(62.97-81.32 \%)\end{array}$ & & $\begin{array}{c}79.77 \% \\
(71.62-88.86 \%)\end{array}$ & \\
\hline Yes & $\begin{array}{c}60.11 \% \\
(37.82-95.55 \%)\end{array}$ & & $\begin{array}{c}46.75 \% \\
(26.17-83.53 \%)\end{array}$ & & $\begin{array}{c}67.53 \% \\
(45.73-99.74 \%)\end{array}$ & \\
\hline RT setting & $3.42(0.98-11.89)$ & 0.053 & $4.03(1.77-9.2)$ & 0.001 & $6.03(2.37-15.32)$ & $<0.01$ \\
\hline Adjuvant RT & $\begin{array}{c}86.98 \% \\
(80.16-94.38 \%)\end{array}$ & & $\begin{array}{c}71.78 \% \\
(63.14-81.59 \%)\end{array}$ & & $\begin{array}{c}81.91 \% \\
(74.08-90.57 \%)\end{array}$ & \\
\hline Pre-operative RT & $\begin{array}{c}67.5 \% \\
(43.03-100 \%)\end{array}$ & & $\begin{array}{c}30 \% \\
(11.64-77.32 \%)\end{array}$ & & $\begin{array}{c}36 \% \\
(14.98-86.49 \%)\end{array}$ & \\
\hline RT interruption & $1.39(0.32-6.05)$ & 0.66 & $1.72(0.67-4.41)$ & 0.26 & $2.81(1.05-7.48)$ & 0.039 \\
\hline No & $\begin{array}{c}86.03 \% \\
(79.02-93.66 \%)\end{array}$ & & $\begin{array}{c}69.84 \% \\
(61.07-79.87 \%)\end{array}$ & & $\begin{array}{c}81.31 \% \\
(73.47-89.99 \%)\end{array}$ & \\
\hline Yes & $\begin{array}{c}76.19 \% \\
(52.08-100 \%)\end{array}$ & & $\begin{array}{c}50 \% \\
(26.9-92.93 \%)\end{array}$ & & $\begin{array}{c}50 \% \\
(26.9-92.93 \%)\end{array}$ & \\
\hline RT beam type & $0.66(0.21-2.11)$ & 0.482 & $0.56(0.25-1.26)$ & 0.164 & $0.4(0.14-1.2)$ & 0.104 \\
\hline Photons & $\begin{array}{c}85.58 \% \\
(76.38-95.89 \%)\end{array}$ & & $\begin{array}{c}66.87 \% \\
(55.72-80.25 \%)\end{array}$ & & $\begin{array}{c}73.66 \% \\
(62.76-86.46 \%)\end{array}$ & \\
\hline Electrons & $\begin{array}{c}90.8 \% \\
(81.39-100 \%)\end{array}$ & & $\begin{array}{c}78.98 \% \\
(66.25-94.14 \%)\end{array}$ & & $\begin{array}{c}90.63 \% \\
(81.03-100 \%)\end{array}$ & \\
\hline
\end{tabular}

\subsection{Toxicity}

Radiation-related adverse events were limited to acute skin toxicity ( $22 \%$ of grade 2 and $2 \%$ of grade 3 dermatitis); no late cardiovascular or pulmonary radiation-induced toxicity was reported (Table 4). Because of radiodermatitis or pain, ten patients had a temporary interruption of radiotherapy or a cancellation of one or two fractions.

Table 4. Toxicity profile.

\begin{tabular}{ccccc}
\hline & \multicolumn{4}{c}{ Toxicity Grade (CTCAE v5) } \\
\hline & $\mathbf{1}$ & $\mathbf{2}$ & $\mathbf{3}$ & $\mathbf{4}-\mathbf{5}$ \\
\hline Acute & $\mathrm{n}=40(35 \%)$ & $\mathrm{n}=25(22 \%)$ & $\mathrm{n}=2(2 \%)$ & - \\
Dermatitis & $\mathrm{n}=1(1 \%)$ & - & - & - \\
Dysphagia & - & $\mathrm{n}=1(1 \%)$ & - & - \\
Pain & - & - & $\mathrm{n}=1(1 \%) *$ & - \\
Cardiovascular & $\mathrm{n}=1(1 \%)$ & - & - & - \\
Late & $\mathrm{n}=1(1 \%)^{* *}$ & - & - & - \\
Edema & - & $\mathrm{n}=1(1 \%)$ & - \\
Pulmonary & Asthenia &
\end{tabular}

* Hypokinetic cardiomyopathy with LADCA (left anterior descending coronary artery) stenosis, not related to RT. ** Bronchial hyperreactivity, not related to RT.

\section{Discussion}

Our population was quite similar to that of previous cohort studies.

The majority of patients were diagnosed with aggressive clinicopathological features (high prevalence of clinical nodal involvement and grade III).

Consistently with what Gutierrez Barrera et al. reported [15], germline BRCA mutations are not more prevalent in IBC than in the non-IBC population. Lobular invasive carcinomas account for about $6 \%$ of our cohort, which is lower than the $10-15 \%$ reported in non-IBC $[16,17]$.

It is important to notice that, as reported elsewhere, TNBC and HER2+ subtypes are more prevalent in IBC than in non-IBC $[8,9,18,19]$. We even had a tendency towards an 
overrepresentation of TNBC (34.6\%) compared to previous cohorts which reported rates of TNBC not exceeding $26 \%$. This might be explained by our relatively small sample, a tertiary referral hospital bias, and maybe a different ethnic distribution (Biswas et al. reported the highest frequency of TNBC among Black patients [8]).

Patients in our cohort benefited from progress made in the systemic treatment of breast cancers with a high proportion of taxane and anthracycline-containing regimens. HER2 inhibitors were used when indicated. Very few patients not achieving pCR received adjuvant capecitabine, given that the results of the CREATE- $X$ study were published recently in 2017 [20]. Similarly, only one patient with HER2+ IBC not in pCR after neoadjuvant systemic treatment underwent adjuvant TDM-1, based on the KATHERINE trial published in 2019 [21].

One-third of our patients received electron-based irradiation to the chest wall while the other received photons to the chest wall, using standard fractionation.

Five-year OS, DFS and LRRFS were 78\% (CI: 70.1-86.8\%), 68.1\% (59.6-77.7\%), and $85.2 \%(78.4-92.7 \%)$, respectively. These survival outcomes are much better than in historical cohorts, which reported 5-year OS between 50 and 65\% [3-6,8,9].

These good results might be explained by the progress made in systemic treatment. Specific treatments for IBC have been tried, such as the addition of bevacizumab (BEVERLY1 and BEVERLY-2 trials [22,23]) or repeated hematopoietic stem cell support (PEGASE 02, 05, and $07[24,25])$, but both failed to become standards of care because of the absence or paucity of clinical benefit with increased toxicity. Nevertheless, non-metastatic IBC management benefited from progress made in non-IBC, particularly from HER2 inhibitors.

Our good survival results might also be explained by the systematic use of multidisciplinary management (trimodality), while in the cohort of non-metastatic IBC reported by van Uden et al. [9], trimodality was used in only 53\% of patients. Another example is the cohort of patients treated with radiotherapy between 1977 and 2004 at MD Anderson Cancer Center, presented by Bristol [3], which showed a 5-year OS of 51\%. Twenty-five percent of patients did not receive complete trimodality treatment in this study because of disease progression during treatment and very few received HER2-targeted therapy.

Although our survival outcomes were better than previously reported in the literature of IBC, it remains poorer than in non-IBC. Comparatively, Grellier et al. found a 5-year OS of $90.9 \%$ and a 5 -year LRRFS of $90.0 \%$ in women treated with post-mastectomy electron radiotherapy for non-IBC [12].

Our high locoregional control is similar to that reported in previous radiotherapy studies in which 5-year LRRFS ranged from 79 to $87 \%$ [3-6], suggesting the validity of radiotherapy techniques used at our institution.

Boulle et al. reported a reduced risk of locoregional recurrence with electrons compared to photons for post-mastectomy irradiation of non-IBC at our center [13]. Here we reported no statistically significant difference between these two irradiation modalities in IBC. This might be explained by the clinical relevance of lymph node metastatic involvement in IBC, which is targeted by photons in both irradiation modalities.

Bristol et al. did not find a benefit of accelerated hyperfractionated radiotherapy but found a better locoregional control with a dose escalation to 66 Gy compared to 60 Gy in women under the age of 45 or with positive margins or not having responded to chemotherapy [3]. In our cohort, patients were treated with standard fractionation (median dose 50 Gy in 2 Gy fractions) and we found a similar locoregional control rate compared to the $84 \%$ 5-year LRRFS reported at MD Anderson. Young age was not found to be an adverse prognosis factor in univariate or multivariate analysis in our cohort.

The diameter of the mass on breast imaging was not found to be a prognosis factor. This highlights the relevance of TNM classification: T4d breast cancers should not be subdivided into different classes according to the diameter of the tumor.

The pathological complete response rate was $32.7 \%$ in our cohort, similar to the $31 \%$ reported in both IBC and locally advanced breast cancers by Monneur et al. [26]. Pathological complete response was found to be associated with OS, DFS, and LRRFS. This 
has been previously observed in IBC studies [8,9], consistently with what is already known in non-IBC [27].

Preoperative radiotherapy was found to be associated with a poorer DFS and OS in multivariate analysis. This can be explained by possible confounding factors not taken into account in regression analysis because preoperative radiotherapy was usually performed in our center for patients with pejorative prognosis who poorly responded to chemotherapy.

The toxicity profile of radiotherapy was good in our cohort. In particular, no late cardiovascular or pulmonary radiation-induced toxicity was reported. Yet the follow-up (54 months) might be a bit short to detect cardiovascular events in our cohort of 113 patients.

Suspension of radiotherapy because of radiodermatitis was found to be associated with poorer OS in univariate analysis and it was close to statistical significance in multivariate analysis, suggesting that radiotherapy should not be interrupted because of manageable acute skin toxicity.

\section{Conclusions}

Despite the limitation due to the retrospective nature of this study, we reported high locoregional control with multidisciplinary management of non-metastatic inflammatory breast cancers and the use of either photon or electron radiotherapy. OS and DFS were found to be better than in historical cohorts, probably because of progress made in systemic treatment including HER2 targeted therapy. Yet, survival remains poorer than in noninflammatory breast cancers, particularly in the non-pCR group, and could be improved in the future with PARP inhibitors (RADIOPARP trial [28]) or immune therapy (PELICAN-IPC 2015-016/Oncodistinct-003 trial [29]).

Author Contributions: Conceptualization, B.N. and Y.K.; methodology, B.N., P.L. and Y.K.; software, P.L.; validation, Y.K., A.F., F.L., J.-Y.P. and D.L.; formal analysis, P.L.; investigation, B.N.; resources, Y.K.; data curation, B.N., P.L.; writing—original draft preparation, B.N.; writing-review and editing, B.N., P.L. and Y.K.; visualization, B.N.; supervision, Y.K.; project administration, Y.K. All authors have read and agreed to the published version of the manuscript.

Funding: This research received no external funding.

Institutional Review Board Statement: The study was conducted according to the guidelines of the Declaration of Helsinki, and approved by the Institutional Review Board of CURIE INSTITUTE (protocol code 200146, 29 April 2020).

Informed Consent Statement: Informed consent was obtained from all subjects involved in the study.

Data Availability Statement: Data are stored in an institutional database.

Conflicts of Interest: The authors declare no conflict of interest. 


\section{Appendix A}

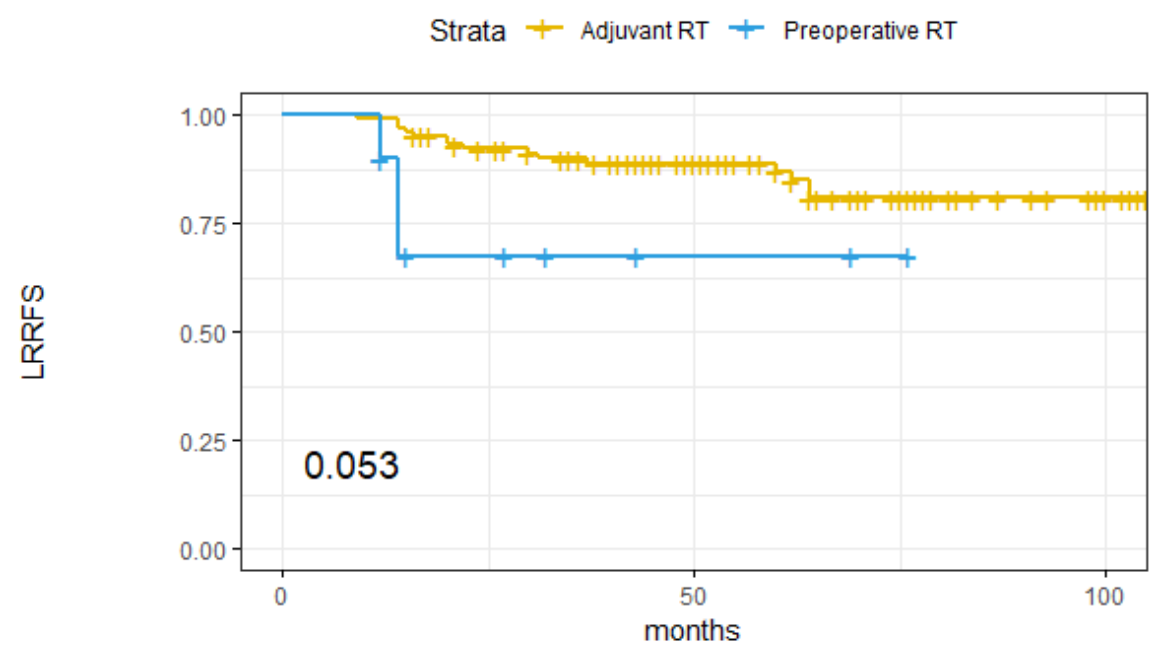

\begin{tabular}{r|ccc|}
\multicolumn{3}{c}{ Number at risk } \\
\cline { 2 - 4 } Adjuvant RT & 103 & 63 & 11 \\
Preoperative RT & 10 & 2 & 0 \\
\hline
\end{tabular}

Figure A1. LRRFS with adjuvant radiotherapy (5-y LRRFS: 87.0\% [80.2-94.4\%]) vs. with preoperative radiotherapy $(67.5 \%[43-100 \%])$.

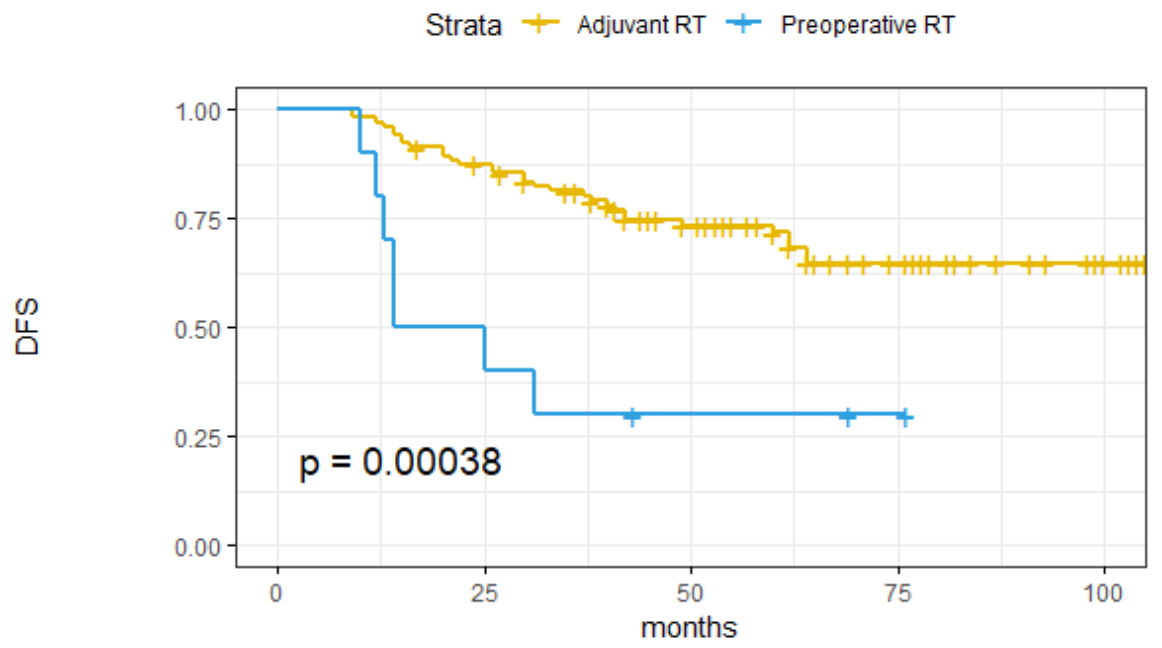

\begin{tabular}{r|c|c|c|c|c|}
\multicolumn{5}{l}{ Number at risk } \\
\cline { 2 - 6 } Adjuvant RT & 103 & 87 & 57 & 28 & 11 \\
Preoperative RT & 10 & 5 & 2 & 1 & 0 \\
\hline
\end{tabular}

Figure A2. DFS with adjuvant radiotherapy (5-y DFS: 71.8\% [63.1-81.6\%]) vs. with preoperative radiotherapy $(30.0 \%[11.6-77.3 \%])$ 


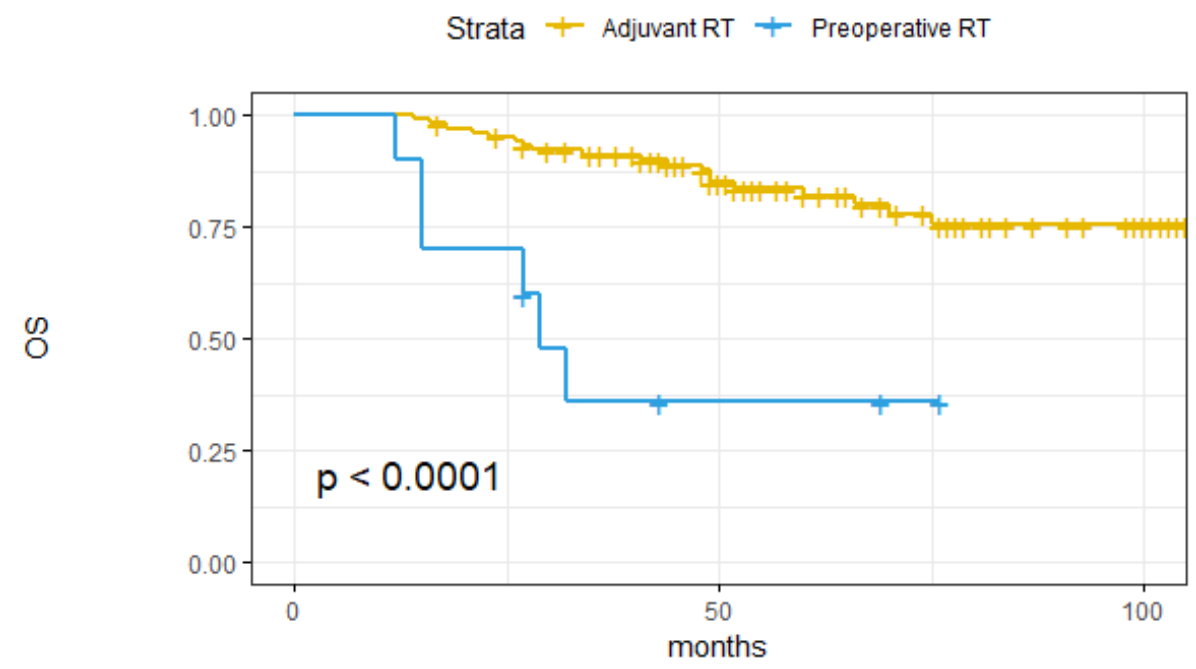

Number at risk

\begin{tabular}{c|c|ccc|}
\cline { 2 - 5 } Adjuvant RT & 103 & 65 & 13 \\
Preoperative RT & 10 & 2 & 0 \\
\cline { 2 - 5 } & & & &
\end{tabular}

Figure A3. OS with adjuvant radiotherapy (5-y OS: 81.9\% [74.1-90.6\%]) vs. with preoperative radiotherapy $(36.0 \%$ [15.0-86.5\%]).

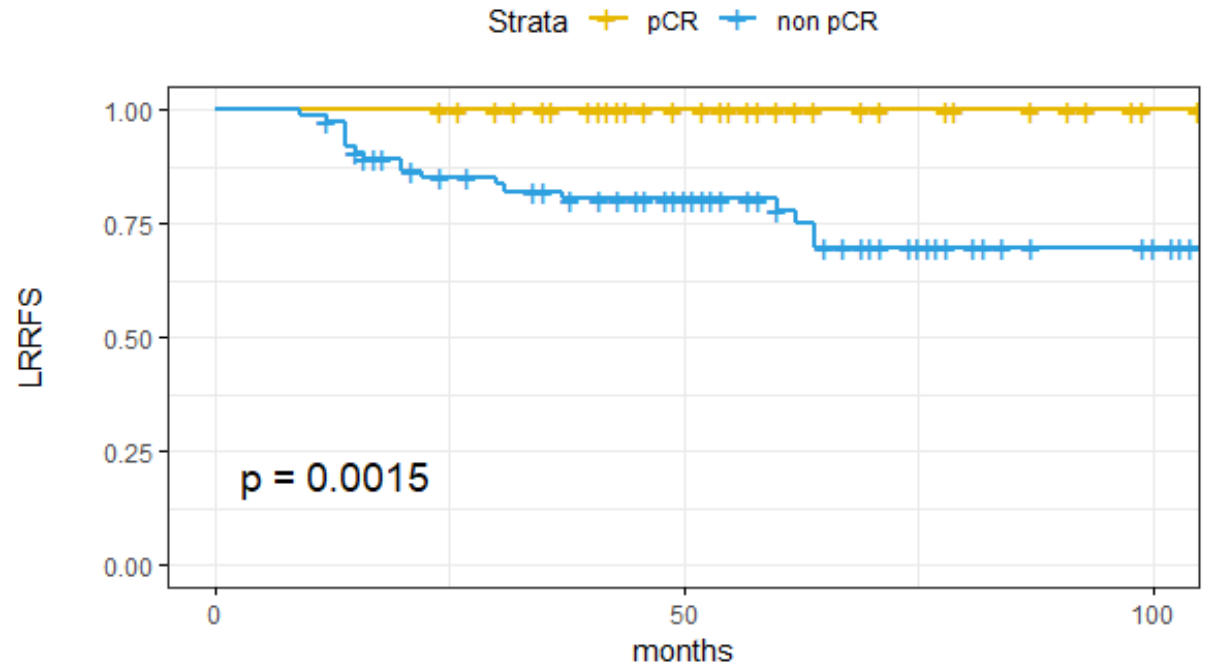

\section{Number at risk}

\begin{tabular}{l|lll|}
\cline { 2 - 3 } $\operatorname{non} p C R$ & 24 & 4 \\
& 37 & 41 & 7 \\
\hline
\end{tabular}

Figure A4. LRRFS in patients achieving pCR (5-y LRRFS: 100\% [100-100\%]) and those not achieving pCR $(77.9 \%$ [68.3-88.8\%]). 


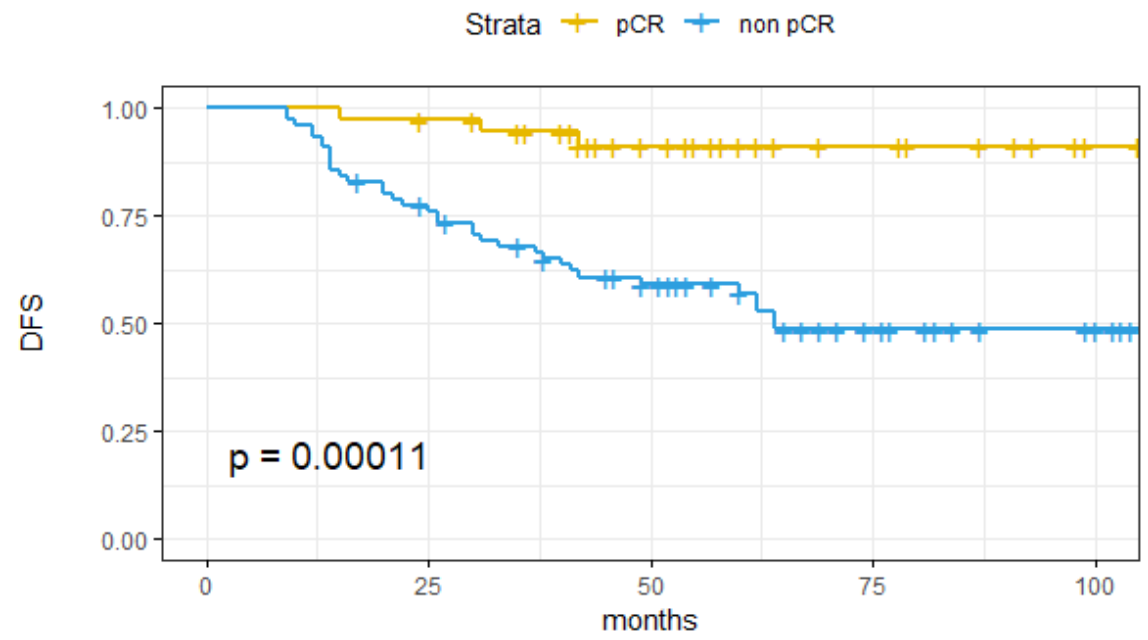

Number at risk

\begin{tabular}{r|l|l|l|l|l|}
\hline \multirow{n}{*}{$\mathrm{pCR}$} & 37 & 35 & 23 & 12 & 4 \\
\hline non $\mathrm{pCR}$ & 76 & 57 & 36 & 17 & 7 \\
\hline
\end{tabular}

Figure A5. DFS in patients achieving pCR (5-y DFS: 91.2\% [82.1-100\%]) and those not achieving pCR $(57.1 \%[46.6-70.0 \%])$.

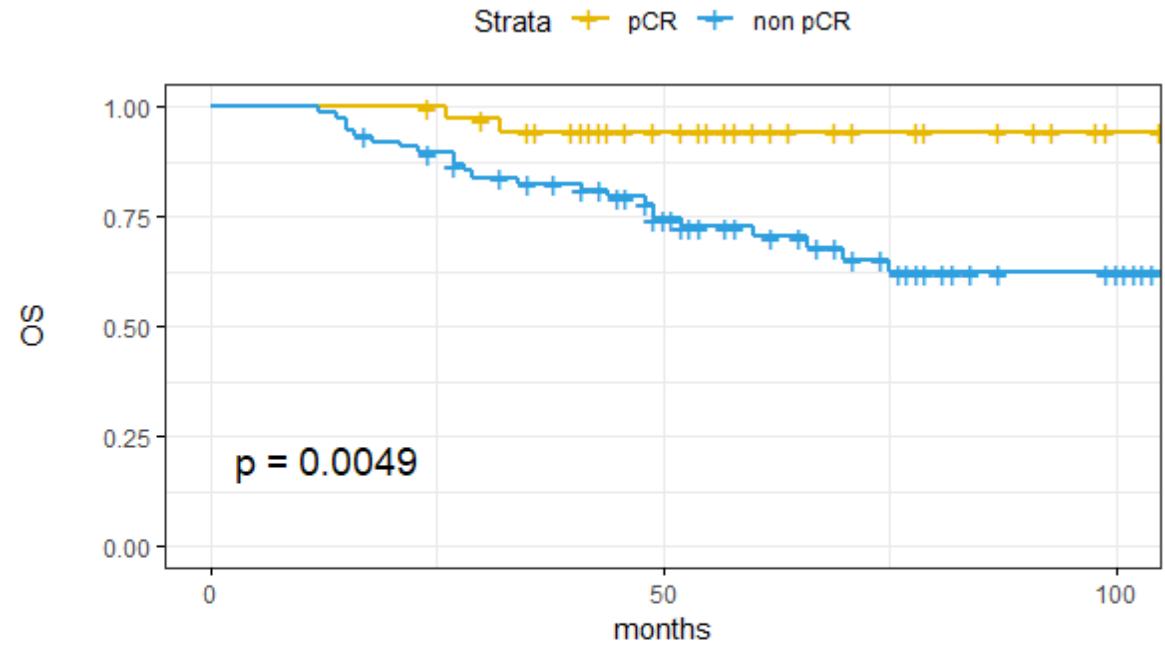

Number at risk

\begin{tabular}{r|c|cc|}
\cline { 2 - 4 } $\operatorname{pCR}$ & 37 & 24 & 4 \\
non $\mathrm{PCR}$ & 76 & 43 & 9 \\
\hline
\end{tabular}

Figure A6. OS in patients achieving pCR (5-y OS: 94.4\% [87.1-100\%]) and those not achieving pCR (70.5\% [59.9-82.3\%]).

\section{References}

1. Hance, K.W.; Anderson, W.F.; Devesa, S.S.; Young, H.A.; Levine, P.H. Trends in Inflammatory Breast Carcinoma Incidence and Survival: The Surveillance, Epidemiology, and End Results Program at the National Cancer Institute. J. Natl. Cancer Inst. 2005, 97, 966-975. [CrossRef] [PubMed]

2. Brierley, J.G.M.; Wittekind, C.H. TNM Classification of Malignant Tumours, 8th ed.; Wiley: Hoboken, NJ, USA, 2007. Available online: https:/ / www.wiley.com/en-au/TNM+Classification+of+Malignant+Tumours\%2C+8th+Edition-p-9781119263579 (accessed on 3 October 2021). 
3. Bristol, I.J.; Woodward, W.A.; Strom, E.A.; Cristofanilli, M.; Domain, D.; Singletary, S.E.; Perkins, G.H.; Oh, J.L.; Yu, T.-K.; Terrefe, W.; et al. Locoregional Treatment Outcomes After Multimodality Management of Inflammatory Breast Cancer. Int. J. Radiat. Oncol. Biol. Phys. 2008, 72, 474-484. [CrossRef]

4. Damast, S.; Ho, A.Y.; Montgomery, L.; Fornier, M.N.; Ishill, N.; Elkin, E.; Beal, K.; McCormick, B. Locoregional Outcomes of Inflammatory Breast Cancer Patients Treated with Standard Fractionation Radiation and Daily Skin Bolus in the Taxane Era. Int. J. Radiat. Oncol. Biol. Phys. 2010, 77, 1105-1112. [CrossRef] [PubMed]

5. Abrous-Anane, S.; Savignoni, A.; Daveau, C.; Pierga, J.-Y.; Gautier, C.; Reyal, F.; Dendale, R.; Campana, F.; Kirova, Y.M.; Fourquet, A.; et al. Management of Inflammatory Breast Cancer after Neoadjuvant Chemotherapy. Int. J. Radiat. Oncol. Biol. Phys. 2011, 79, 1055-1063. [CrossRef] [PubMed]

6. Brown, L.; Harmsen, W.; Blanchard, M.; Goetz, M.; Jakub, J.; Mutter, R.; Petersen, I.; Rooney, J.; Stauder, M.; Yan, E.; et al. Once-Daily Radiation Therapy for Inflammatory Breast Cancer. Int. J. Radiat. Oncol. Biol. Phys. 2014, 89, 997-1003. [CrossRef]

7. Genet, D.; Lejeune, C.; Bonnier, P.; Aubard, Y.; Venat-Bouvet, L.; Adjadj, D.J.; Martin, J.; Labourey, J.L.; Benyoub, A.; Clavère, P.; et al. Concomitant Intensive Chemoradiotherapy Induction in Non-Metastatic Inflammatory Breast Cancer: Long-Term Follow-Up. Br. J. Cancer 2007, 97, 883-887. [CrossRef]

8. Biswas, T.; Jindal, C.; Fitzgerald, T.L.; Efird, J.T. Pathologic Complete Response (PCR) and Survival of Women with Inflammatory Breast Cancer (IBC): An Analysis Based on Biologic Subtypes and Demographic Characteristics. Int. J. Environ. Res. Public Health 2019, 16, 124. [CrossRef]

9. Van Uden, D.J.P.; van Maaren, M.C.; Bult, P.; Strobbe, L.J.A.; van der Hoeven, J.J.M.; Blanken-Peeters, C.F.J.M.; Siesling, S.; de Wilt, J.H.W. Pathologic Complete Response and Overall Survival in Breast Cancer Subtypes in Stage III Inflammatory Breast Cancer. Breast Cancer Res. Treat. 2019, 176, 217-226. [CrossRef]

10. Wingo, P.A.; Jamison, P.M.; Young, J.L.; Gargiullo, P. Population-Based Statistics for Women Diagnosed with Inflammatory Breast Cancer (United States). Cancer Causes Control 2004, 15, 321-328. [CrossRef]

11. Rueth, N.M.; Lin, H.Y.; Bedrosian, I.; Shaitelman, S.F.; Ueno, N.T.; Shen, Y.; Babiera, G. Underuse of Trimodality Treatment Affects Survival for Patients with Inflammatory Breast Cancer: An Analysis of Treatment and Survival Trends from the National Cancer Database. J. Clin. Oncol. 2014, 32, 2018-2024. [CrossRef]

12. Grellier Adedjouma, N.; Chevrier, M.; Fourquet, A.; Costa, E.; Xu, H.; Berger, F.; Campana, F.; Laki, F.; Beuzeboc, P.; Lefeuvre, D.; et al. Long-Term Results of a Highly Performing Conformal Electron Therapy Technique for Chest Wall Irradiation after Mastectomy. Int. J. Radiat. Oncol. Biol. Phys. 2017, 98, 206-214. [CrossRef] [PubMed]

13. Boulle, G.; Saint-Martin, C.; De La Lande, B.; Laki, F.; Bidoz, N.F.; Berger, F.; Veret, A.; Bragard, C.; Fourquet, A.; Kirova, Y.M. Photons without Bolus Versus Electrons with Bolus after Upfront Mastectomy without Immediate Reconstruction in Breast Cancer Patients. Int. J. Radiat. Oncol. Biol. Phys. 2019, 104, 877-884. [CrossRef]

14. Hudis, C.A.; Barlow, W.E.; Costantino, J.P.; Gray, R.J.; Pritchard, K.I.; Chapman, J.-A.W.; Sparano, J.A.; Hunsberger, S.; Enos, R.A.; Gelber, R.D.; et al. Proposal for Standardized Definitions for Efficacy End Points in Adjuvant Breast Cancer Trials: The STEEP System. J. Clin. Oncol. 2007, 25, 2127-2132. [CrossRef] [PubMed]

15. Gutierrez Barrera, A.M.; Fouad, T.M.; Song, J.; Webster, R.; Elsayegh, N.; Wood, A.L.; Demir, A.; Litton, J.K.; Ueno, N.T.; Arun, B.K. BRCA Mutations in Women with Inflammatory Breast Cancer. Cancer 2018, 124, 466-474. [CrossRef]

16. Li, C.I.; Anderson, B.O.; Daling, J.R.; Moe, R.E. Trends in Incidence Rates of Invasive Lobular and Ductal Breast Carcinoma. JAMA 2003, 289, 1421-1424. [CrossRef]

17. Raghav, K.; French, J.T.; Ueno, N.T.; Lei, X.; Krishnamurthy, S.; Reuben, J.M.; Valero, V.; Ibrahim, N.K. Inflammatory Breast Cancer: A Distinct Clinicopathological Entity Transcending Histological Distinction. PLoS ONE 2016, 11, e0145534. [CrossRef]

18. Matro, J.M.; Li, T.; Cristofanilli, M.; Hughes, M.E.; Ottesen, R.A.; Weeks, J.C.; Wong, Y.-N. Inflammatory Breast Cancer Management in the National Comprehensive Cancer Network: The Disease, Recurrence Pattern, and Outcome. Clin. Breast Cancer 2015, 15, 1-7. [CrossRef]

19. Masuda, H.; Brewer, T.M.; Liu, D.D.; Iwamoto, T.; Shen, Y.; Hsu, L.; Willey, J.S.; Gonzalez-Angulo, A.M.; Chavez-MacGregor, M.; Fouad, T.M.; et al. Long-Term Treatment Efficacy in Primary Inflammatory Breast Cancer by Hormonal Receptor- and HER2Defined Subtypes. Ann. Oncol. 2014, 25, 384-391. [CrossRef]

20. Masuda, N.; Lee, S.-J.; Ohtani, S.; Im, Y.-H.; Lee, E.-S.; Yokota, I.; Kuroi, K.; Im, S.-A.; Park, B.-W.; Kim, S.-B.; et al. Adjuvant Capecitabine for Breast Cancer after Preoperative Chemotherapy. N. Engl. J. Med. 2017, 376, 2147-2159. [CrossRef] [PubMed]

21. Von Minckwitz, G.; Huang, C.-S.; Mano, M.S.; Loibl, S.; Mamounas, E.P.; Untch, M.; Wolmark, N.; Rastogi, P.; Schneeweiss, A.; Redondo, A.; et al. Trastuzumab Emtansine for Residual Invasive HER2-Positive Breast Cancer. N. Engl. J. Med. 2019, 380, 617-628 [CrossRef]

22. Bertucci, F.; Fekih, M.; Autret, A.; Petit, T.; Dalenc, F.; Levy, C.; Romieu, G.; Bonneterre, J.; Ferrero, J.-M.; Kerbrat, P.; et al. Bevacizumab plus Neoadjuvant Chemotherapy in Patients with HER2-Negative Inflammatory Breast Cancer (BEVERLY-1): A Multicentre, Single-Arm, Phase 2 Study. Lancet Oncol. 2016, 17, 600-611. [CrossRef]

23. Pierga, J.-Y.; Petit, T.; Delozier, T.; Ferrero, J.-M.; Campone, M.; Gligorov, J.; Lerebours, F.; Roché, H.; Bachelot, T.; Charafe-Jauffret, E.; et al. Neoadjuvant Bevacizumab, Trastuzumab, and Chemotherapy for Primary Inflammatory HER2-Positive Breast Cancer (BEVERLY-2): An Open-Label, Single-Arm Phase 2 Study. Lancet Oncol. 2012, 13, 375-384. [CrossRef] 
24. Gonçalves, A.; Pierga, J.-Y.; Ferrero, J.-M.; Mouret-Reynier, M.-A.; Bachelot, T.; Delva, R.; Fabbro, M.; Lerebours, F.; Lotz, J.-P.; Linassier, C.; et al. UNICANCER-PEGASE 07 Study: A Randomized Phase III Trial Evaluating Postoperative Docetaxel-5FU Regimen after Neoadjuvant Dose-Intense Chemotherapy for Treatment of Inflammatory Breast Cancer. Ann. Oncol. 2015, 26, 1692-1697. [CrossRef] [PubMed]

25. Viens, P.; Palangié, T.; Janvier, M.; Fabbro, M.; Roché, H.; Delozier, T.; Labat, J.P.; Linassier, C.; Audhuy, B.; Feuilhade, F.; et al. First-Line High-Dose Sequential Chemotherapy with RG-CSF and Repeated Blood Stem Cell Transplantation in Untreated Inflammatory Breast Cancer: Toxicity and Response (PEGASE 02 Trial). Br. J. Cancer 1999, 81, 449-456. [CrossRef]

26. Monneur, A.; Goncalves, A.; Gilabert, M.; Finetti, P.; Tarpin, C.; Zemmour, C.; Extra, J.-M.; Tallet, A.; Lambaudie, E.; Jacquemier, J.; et al. Similar Response Profile to Neoadjuvant Chemotherapy, but Different Survival, in Inflammatory versus Locally Advanced Breast Cancers. Oncotarget 2017, 8, 66019-66032. [CrossRef] [PubMed]

27. Symmans, W.F.; Wei, C.; Gould, R.; Yu, X.; Zhang, Y.; Liu, M.; Walls, A.; Bousamra, A.; Ramineni, M.; Sinn, B.; et al. Long-Term Prognostic Risk after Neoadjuvant Chemotherapy Associated with Residual Cancer Burden and Breast Cancer Subtype. J. Clin. Oncol. 2017, 35, 1049-1060. [CrossRef] [PubMed]

28. Loap, P.; Loirat, D.; Berger, F.; Ricci, F.; Vincent-Salomon, A.; Ezzili, C.; Mosseri, V.; Fourquet, A.; Ezzalfani, M.; Kirova, Y. Combination of Olaparib and Radiation Therapy for Triple Negative Breast Cancer: Preliminary Results of the RADIOPARP Phase 1 Trial. Int. J. Radiat. Oncol. Biol. Phys. 2021, 109, 436-440. [CrossRef]

29. Bertucci, A.; Bertucci, F.; Zemmour, C.; Lerebours, F.; Pierga, J.-Y.; Levy, C.; Dalenc, F.; Grenier, J.; Petit, T.; Berline, M.; et al. PELICAN-IPC 2015-016/Oncodistinct-003: A Prospective, Multicenter, Open-Label, Randomized, Non-Comparative, Phase II Study of Pembrolizumab in Combination with Neo Adjuvant EC-Paclitaxel Regimen in HER2-Negative Inflammatory Breast Cancer. Front. Oncol. 2020, 10, 575978. [CrossRef] 